\title{
ADAPTASI MASYARAKAT TERHADAP BENCANA LETUSAN GUNUNG KERINCI DI DESA GUNUNG LABU KECAMATAN KAYUARO BARAT KABUPATEN KERINCI
}

\author{
Florian Yulisar ${ }^{1}$ Dedi Hermon ${ }^{2}$ Endah Purwaningsih ${ }^{2}$ \\ Program Studi Pendidikan Geografi, \\ Fakultas Ilmu Sosial, Universitas Negeri Padang \\ Email: florianyulisar1305993@gmail.com
}

\begin{abstract}
Abstrak
Penelitian ini bertujuan untuk mengetahui adaptasi masyarakat terhadap bencana letusan Gunung Kerinci di Desa Gunung Labu Kecamatan Kayu Aro Barat Kabupaten Kerinci. Jenis penelitian adalah penelitian kualitatif. Subjek penelitian yaitu Pemerintah Desa Gunung Labu, tokoh masyarakat dan masyarakat.Teknik pengumpulan data yang digunakan adalah observasi, wawancara dan dokumentasi. Analisis data meliputi reduksi data, penyajian data dan penarikan kesimpulan. Hasil penelitian menemukan bahwa pengetahuan masyarakat terhadap bahaya dan resiko tinggal di daerah yang rawan terhadap bencana letusan gunung dikategorikan baik. Adaptasi yang dilakukan masyarakat Desa Gunung Labu terhadap bencana letusan gunung: 1) Pembangunan pondasi, tembok dan atap rumah yang kuat agar tidak mudah roboh jika terjadi bencana. 2) Pemakaian pakaian yang lebih tebal dan masker pada pagi dan malam hari karena daerah yang dingin dan untuk melindungi diri dari abu vulkanik. 3) Masyarakat mengumpulkan makanan dan minuman yang mudah dimasak dan ditemukan di sekitar mereka. 4) Pada tanaman perkebunan masyarakat menyesuaikan tanaman pertanian dengan menanam tanaman perkebunan yang cepat masa panennya dan melihat situasi cuaca.
\end{abstract}

Kata Kunci : Adaptasi, Masyarakat, Bencana Letusan

\begin{abstract}
This study aims to determine the community adaptation to the disaster of the Mount Kerinci eruption in Gunung Labu Village, Kayu Aro Barat District, Kerinci Regency. This type of research is qualitative research. The research subjects were the Government of Gunung Labu Village, community and community leaders. Data collection techniques used were observation, interviews and documentation. Data analysis includes data reduction, data presentation and conclusion drawing. The results of the study found that people's knowledge of the dangers and risks of living in areas prone to volcanic eruptions was categorized as good. Adaptation carried out by the people of Gunung Labu Village to the volcanic eruption: 1) Construction of strong foundations, walls and roofs so as not to collapse easily in the event of a disaster. 2) Use thicker clothes and masks in the morning and evening because of cold areas and to protect themselves from volcanic ash. 3) People collect food and drinks that are easily cooked and found around them. 4) In plantation crops the community adjusts agricultural crops by planting plantation crops that are fast harvesting and looking at the weather situation.
\end{abstract}

Keywords: Adaptation, Society, Eruption Disaster

\footnotetext{
${ }^{1}$ Mahasiswa Program Studi Pendidikan Geografi

${ }^{2}$ Dosen Jurusan Geografi Fakultas Ilmu Sosial Universitas Negeri Padang,
} 


\section{PENDAHULUAN}

Indonesia terletak di antara tiga pertemuan lempeng tektonik yaitu lempeng Indo-Australia yang bergerak ke utara, lempeng Eurasia yang bergerak ke selatan, dan lempeng Pasifik yang bergerak dari timur ke barat. Akibat pertemuan tiga lempeng tersebut menyebabkan terjadinya penekanan pada lapisan bawah bumi yang mengakibatkan wilayah Negara Indonesia memiliki morfologi yang bergunung-gunung dan relief yang relatif kasar. Indonesia juga merupakan Negara cincin api di dunia karena dikelilingi oleh deretan Gunung api aktif dari barat hingga timur. Oleh sebab itu, berbagai fenomena seperti gempa bumi dan erupsi Gunung api sering terjadi di Indonesia (Hermon, 2015).

Hal ini disebabkan Indonesia berada pada jalur aktivitas tektonik sekaligus vulkanik bumi. Kedua aktivitas ini merupakan proses alamiah planet bumi yang selalu bergerak (Priambodo, 2009). Pulau Sumatera terletak pada batas lempeng konvergen antara lempeng Indo-Australia dan Lempeng Eurasia yaitu lempeng Indo-Australia menunjam di bawah lempeng Eurasi dan menghasilkan zona subduksi. Pertemuan kedua lempeng ini menghasilkan getaran gempa dengan intensitas kekuatan yang berbedabeda. Selain itu, dengan adanya zona subduksi maka Indonesia juga banyak terdapat gunung api terutama di sepanjang Pulau Sumatera, Jawa dan Nusa Tenggara. ialah salah satu daerah yang paling dekat dengan Gunung Kerinci, sehingga daerah ini memiliki dampak bencana yang pertama kali terkena bencana dari Gunung Kerinci baik itu bencana Gunung meletus, erupsi dan gempa bumi yang ditimbulkan oleh Gunung Kerinci tersebut. Selain itu keadaan masyarakat yang tidak tanggap terhadap bencana Gunung Kerinci akan memicu banyaknya jumlah korban. Kesiapan atau adaptasi masyarakat dalam menghadapi terjadinya bencana tidak lepas pula dari adanya penyuluhan dan pelatihan yang dilakukan oleh lembaga pemerintah yang bertugas mengurangi risiko bencana.

Adaptasi manusia adalah proses penyesuaian diri terhadap keadaan lingkungan yang berubah di sekitar, dengan tidak bermaksud untuk menghilangkan perubahan lingkungan yang terjadi dalam Aditya Listiyan Sutigno (2015).

Sedangkan Bencana ialah salah satu kejadian alam, buatan manusia, atau perpaduan antara keduanya yang terjadi secara tiba-tiba sehingga menimbulkan dampak negatif yang dahsyat bagi kelangsungan kehidupan. Dalam kejadian tersebut, unsur yang berkaitan langsung atau terpengaruh harus merespon dengan melakukan tindakan luar biasa, guna untuk menyesuaikan dan sekaligus memulihkan kondisi seperti semula atau menjadi lebih baik (Priambodo, 2009).

Pengelolaan bencana yang efektif memerlukan kombinasi empat konsep, yaitu atas semua bahaya, menyeluruh, terpadu, dan kesiapan masyarakat (Purnomo dan Sugiantoro, 2010). 
Tingkat risiko bencana adalah tingkat kerawanan karena aktivitas manusia yaitu ukuran yang menyatakan besar kecilnya kerugian manusia dari kejadian bencana. Risiko bencana Gunung Kerinci seperti awan panas, hujan abu lebat, lava, gas racun, banjir lahar dingin, banjir bandang, dan longsor vulkanik dalam Hermon (2012).

Berdasarkan masalah di atas peneliti tertarik untuk melakukan penelitian tentang dampak, adaptasi, dan persepsi masyarakat terhadap bencana letusan Gunung Kerinci di Desa Gunung Labu Kecamatan Kayu Aro Barat Kabupaten Kerinci”.

\section{METODE PENELITIAN}

Jenis penelitian ini adalah kualitatif yaitu penelitian yang bertujuan untuk melihat, meninjau, melukiskan dan menggambarkan tentang suatu objek yang diteliti sebagaimana adanya pada saat penelitian berlangsung.

Informan penelitian ini masyarakat yang tinggal di Desa Gunung Labu yang berjumlah 13 orang dan teknik pengambilan informan menggunakan teknik Purposive Sampling.

Teknik pengumpulan data dengan observasi, wawancara, dan studi dokumentasi. Analisis data dengan menggunakan teknik analisis data model interaktif menurut Miles dan Huberman (2007).

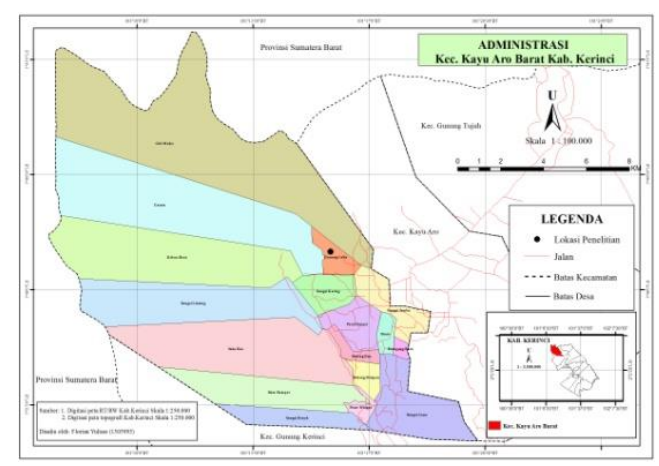

Gambar 1. Peta Lokasi Penelitian

\section{HASIL PENELITIAN}

1. Pengetahuan Masyarakat dalam menghadapi Bencana alam

Berdasarkan hasil wawancara dengan kepala desa, tokoh masyarakat dan masyarakat Desa Gunung Labu dapat disimpulkan bahwa masyarakat sekitar sudah tahu bahwa daerah tempat tinggal mereka rawan terhadap bencana, Karena factor tanah yang subur sehingga membuat masyarakat tetap bertahan di daerah rawan bencana kemudian daerah Gunung Labu dan sekitarnya juga sudah pernah dilakukan simulasi terhadap bencana letusan gunung oleh pemerintah. Dengan diadakan simulasi tersebut mengurangi rasa takut masyarakat Desa Gunung Labu yang tinggal di daerah rawan bencana letusan gunung.

2. Adaptasi kehidupan masyarakat Desa Gunung Labu bencana Letusan Gunung Kerinci

Berdasarkan hasil wawancara dengan masyarakat Desa Gunung Labu dapat disimpulkan bahwa tidak ada tradisi atau peraturan yang mengatakan masyarakat tidak harus membuat rumah sesuai peraturan yang ada. Masyarakat menyesuaikan pembangunan rumah seperti pembangunan dinding rumah dari semen rumah dan atap yang kuat dan 
kokoh, supaya tidak mudah rusak jika terjadi bencana, baik itu gempa bumi, letusan gunung, longsor, banjir lahar dingin dan lahar panas, penyesuaian pada pakaian masyarakat daerah pegunungan yang dingin dan memakai masker agar terhindar dari abu vulkanik dan sering menggunakan pakaian yang tebal, masyarakat mengumpulkan makanan dan minuman yang mudah ditemukan disekitar mereka dan mudah dimasak seperti sayursayuran yang mudah untuk ditanam dan makanan kemasan yang mudah ditemukan di pasaran.

\section{PEMBAHASAN}

1. Pengetahuan masyarakat Desa Gunung Labu tentang bencana, daerah rawan bencana, letusan gunung, resiko bencana sangat baik. Pengetahuan adalah hasil penginderaan manusia, atau hasil tahu seseorang terhadap objek melalui indera yang dimilikinya (mata, telinga, hidung dan sebagainya) dalam Notoatmodjo (2010). Masyarakat tahu apa yang harus dilakukan dan disiapkan sebelum terjadi bencana, saat terjadi bencana dan setalah terjadi bencana. Karena di Desa Gunung Labu ini sudah pernah dilakukan simulasi bencana letusan gunung.

Hal ini sesuai dengan hasil penelitian yang menunjukkan jawaban benar dari informan $\geq 76$ 100\%. Berdasarkan Penelitian Notoatmodjo (2003) Pengukuran Pengetahuan dibagi menjadi 3 (tiga) katagori sebagai berikut:
a) Baik : Jika jawaban benar $\geq 76-100 \%$
b) Cukup : Jika jawaban benar $56-75 \%$

c) Kurang : Jika jawaban benar $\leq 55 \%$

Dalam UU No.11/2014
bencana ialah peristiwa atau
serangkaian peristiwa yang
mengancam dan mengganggu
kehidupan dan penghidupan
masyarakat yang disebabkan, baik oleh faktor alam atau faktor non alam maupun faktor manusia, sehingga mengakibatkan timbulnya korban jiwa manusia, kerusakan lingkungan, kerugian harta benda, dan dampak psikologis.

Sedangkan yang dikatakan masyarakat Desa Gunung Labu bencana merupakan kejadian yang datang secara tiba-tiba dan dapat merugikan baik moril maupun materil dan mengganggu kehidupan manusia. Kemudian masyarakat juga sudah banyak yang tahu jenis-jenis bencana alam, seperti bencana gempa, letusan gunung, banjir, kebakaran.

2. Masyarakat Desa Gunung Labu tahu tingkat resiko tinggal di daerah rawan bencana letusan gunungapi. Menurut Hermon (2012), Tingkat risiko bencana adalah tingkat kerawanan karena aktivitas manusia yaitu ukuran yang menyatakan besar kecilnya kerugian manusia dari kejadian bencana.

Berdasarkan penemuan peneliti yang dilakukan dengan masyarakat Desa Gunung Labu, ditemukan bahwa warga hanya menerima apa yang terjadi pada lahan pertanian dan menunggu bencana selesai. Karena masyarakat sudah tahu apa risiko dan kerugian yang akan mereka alami.

3. Adaptasi yang dilakukan masyarakat Desa Gunung Labu pada perumahan dengan membuat dinding rumah yang terbuat dari semen dan 
kayu yang kuat agar terhindar dari bencana letusan gunung, gempa bumi dan banjir. Pada pakaian masyarakat akan sering memakai masker dan pakaian yang lebih tebal karena daerah yang dingin kemudian agar terhindar dari abu vulkanik. Pada makanan dan minuman yang ada disekitar yang mudah ditemukan, kebanyakan masyarakat lebih mengonsumsi makanan seperti buahbuahan, sayur-sayuran karena mudah untuk ditanam dibandingkan makanan kemasan.

Sesuai yang dikatakan Aditya Listyan Sutigno (2015) adaptasi manusia yaitu sebagai berikut :

a. Adaptasi budaya

Adaptasi kebudayaan yang diartikan sebagai kebiasaankebiasaan penduduk dalam menyikapi keadaan alamnya sehingga terbentuk berbagai kebudayaan. Misalnya, bentuk rumah orang Eskimo yang kecil, pendek, tanpa jendela, dan beratap bulat berguna untuk menanggulangi udara dingin dan beratnya salju yang menempel di bagian luar. Masyarakat yang tinggal di daerah tinggi dengan hawa dingin menggunakan pakaian yang tebal untuk menghindari hilangnya pengeluaran panas yang berlebihan dari tubuhnya. Konstruksi rumah di dataran tinggi biasanya dibangun dengan tembok yang lebih tebal atau dari kayu untuk menjaga kehangatan suhu ruangan. Ventilasi dan jendela besar, kadang banyak agar sirkulasi udara baik mengingat tekanan oksigen di daerah tinggi relatif kecil.

b. Adaptasi bahan makanan

Adaptasi pada bahan makanan yang diartikan bahwa makanan di berbagai daerah yang berbeda-beda sesuai dengan bahan yang tersedia di alam sekitar. Penduduk daerah pegunungan lebih banyak makan sayur-sayuran, penduduk pantai makan ikan, dan penduduk daerah padang rumput makan daging.

c. Adaptasi Rumah

Adaptasi rumah diartikan bahwa setiap daerah mempunyai relief yang berbeda-beda, daerah pegunungan mempunyai relief berbukit-bukit dan bergelombang dan daerah pantai cinderung lebih datar. Penduduk daerah pegunungan lebih banyak membuat rumah di daerah yang lebih tinggi, dinding rumah yang tebal dan jendela rumah yang lebih sedikit agar tidak mudah dimasuki oleh angin dan debu. Karena daerah pegunungan mempunyai hawa yang dingin. Kemudian agar terhindar dari bahaya letusan gunung berapi dan banjir. Penduduk daerah pinggiran pantai mencari daerah yang lebih tinggi dari pantai agar terhindari dari bahaya banjir, tidak membuat rumah lebih dari tiga lantai, pondasi dan dinding rumah yang kuat, mempunyai jendela lebih dari satu. Karena daerah pinggiran pantai mempunyai hawa yang panas.

\section{d. Adaptasi Pakaian}

Adaptasi pakaian diartikan bahwa daerah yang mempunyai hawa yang berbeda-beda. Daerah pegunungan yang mempunyai hawa dingin, penduduk sekitar cinderung memakai pakaian yang lebih tebal dan daerah pinggiran pantai mempunyai hawa panas, penduduk cinderung memakai pakaian yang lebih tipis dan pendek.

\section{e. Adaptasi Ekonomi}

Masyarakat beradaptasi untuk memenuhi kehidupan mereka dengan 
meningkatkan mata pencaharian, yang dulunya petani tambak, sekarang bekerja menjadi buruh untuk mampu beradaptasi.

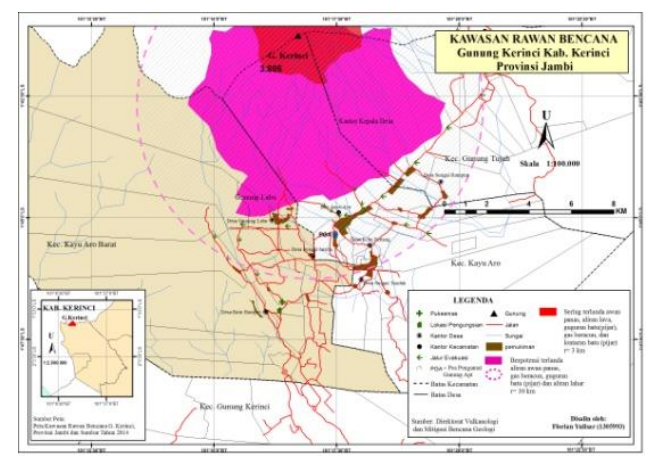

Gambar 2. Peta Kawasan Rawan

Bencana Gunung Kerinci

\section{PENUTUP}

\section{A. Simpulan}

Pengetahuan masyarakat terhadap bahaya dan risiko tinggal di daerah yang rawan terhadap bencana letusan gunung sangat baik, Karena sudah dilakukan simulasi dan berdasarkan pengalaman yang telah sudah terhadap bencana letusan gunungapi. Kemudian masyarakat beradaptasi terhadap pembuatan rumah dengan mendirikan rumah yang kokoh, dinding rumah yang tebal, atap rumah tahan terhadap hujan air dan hujan abu. Pada tanaman pertanian masyarakat menyesuikan tanaman pertanian dengan menanan tanaman pertanian yang masa panennya lebih cepat kemudian melihat situasi dan kondisi ekonomi. Pada makanan dan minuman masyarakat dearah pegunungan beradaptasi dengan mengumpilkan makanan dan minum yang mudah ditemukan disekitar mereka, seperti mengonsumsi sayursayuran, buah-buahan dan makanan kemasan. Pada pakaian masyarakat lebih memakai masker, pakaian yang tebal yang bisa menghangatkan agar terhindar dari dinginnya udara pegunungan dan letusan abu vulkanik.

B. Saran

Berdasarkan temuan peneliti, maka peneliti menyarankan beberapa hal diantaranya :

1. Diharapkan adanya sosialisasi tentang beradaptasi di daerah yang rawan terhadap bencana yang dilakukan sekali setahun supaya warga lebih tau dan lebih berhati-hati menjaga harta benda, keluarga dan lingkungan sekitar.

2. Bagi masyarakat supaya mencari informasi lebih banyak lagi bahaya tinggal di daerah rawan bencana dan bagaimana beradaptasi dengan lingkungan yang sering terkena bencana letusan gunungapi.

\section{DAFTAR PUSTAKA}

Hermon, Dedi. (2012). Mitigasi Bencana Hidrometeorologi. UNP Press Padang.

Hermon, Dedi. (2015). Geografi Bencana Alam. Jakarta: PT Raja Grafindo Persada.

Sutigno, Aditya Listiyan. (2015). Bentuk Adaptasi Masyarakat Terhadap Bencana Rob di Desa Sriwulan Kecamatan Sayung Kabupaten Demak. Halaman: 509,510

Miles, Mattew B dan Amichael Huberman. 2007. Analisis Data Kualitatif Buku Sumber Tentang Metode-Metode Baru. Terjemahan Tjetjep 
Rohrndi Rosihi. Jakarta:

Universitas Indonesia

Notoatmodjo. (2010) Metode penelitian kesehatan, edisi revisi, Rineke Cipta. Jakarta.

Notoatmodjo. 2003. Pendidikan Dan Perilaku Kesehatan. Jakarta: Rineka Cipta.

Priambodo, Ari. (2009). Panduan Praktis Menghadapi Bencana. Yogyakarta:

Kanisius.

Purnomo, Hadi dan $\begin{array}{r}\text { Ronny } \\ \text { Sugiantoro. }\end{array}$
Manajemen Bencana
Respon
dan Tindakan terhadap
Bencana.
MedPress

